\title{
Studies on the conversion of ketones of heterocyclic spiro compounds having barbituric acid moieties into oxime derivatives
}

\author{
M. M. Rahman ${ }^{1}$, M. E. Halim ${ }^{1}$, S. M. Ahmed ${ }^{2}$, K. Akhter ${ }^{1}$, U. K. R. Romman ${ }^{1 *}$ and M. G. Ahmed $^{1}$ \\ ${ }^{1}$ Department of Chemistry, University of Dhaka, Dhaka-1000, Bangladesh \\ ${ }^{2}$ Department of Natural Science, American International University-Bangladesh (AIUB), Banani, Dhaka-1213, \\ Bangladesh
}

\begin{abstract}
Five oxime derivatives 7, 11-bis-(4-chlorophenyl)-3-thioxo-2,4-diazaspiro[5,5] undecane-1,5,9-trione-9-oxime (2a), 7,11-bis-(4methoxyphenyl)-2,4-diazaspiro[5,5] undecane-1,3,5,9-tetraone-9-oxime (2b), 7,11-diphenyl-2,4-diazaspiro[5,5] undecane-1,3,5,9-tetraone9-oxime (2c), 7,11-bis-(4-methoxyphenyl)-3-thioxo-2,4-diazaspiro[5,5] undecane-1,5,9-trione-9-oxime (2d), 7,11-diphenyl-3-thioxo-2,4diazaspiro[5,5] undecane-1,5,9-trione-9-oxime (2e) were synthesized from the corresponding 7,11-diaryl-2,4-diazaspiro[5,5]undecane-3oxo (or thioxo)-1,5,9-triones (1a-e) with hydroxylaminehydrogenchloride in presence of pyrimidine in absolute alcohol. The structures of the compounds $2 \mathrm{a}$-e were confirmed by their UV, IR, ${ }^{1} \mathrm{H}$ NMR, ${ }^{13} \mathrm{C}$ NMR and mass spectral data and elemental analyses.
\end{abstract}

Keywords: Spiro compounds; Oxime derivatives; Barbituric acid; 2-thiobarbituric acid

\section{Introduction}

Conversion of carbonyl functionalities into oximes is an important reaction in organic chemistry. Classically, oximes are prepared (Sandier et. al., 1989) by refluxing an alcoholic solution of a carbonyl compound with hydroxylamine hydrochloride and pyridine. Oximes are highly crystalline compounds that find applications not only for protection, but also for purification and characterization of carbonyl compounds (Sandier et. al., 1989 and Greene et. al., 1999).

They are also useful for selective -activation (Whitesell et al., 1983) and are extensively used as intermediates for the preparation of amides by the Beckmann rearrangement (Ramalingan et. al., 2007 and Furuya et. al., 2005) and fungicides and herbicides (Song et. al., 2005). In inorganic chemistry, oximes act as a versatile ligand.

On the other hand, spiro-pyrimidinetriones or pyrimidinediones having barbituric acid or thiobarbituric acid moieties exhibit chemotherapeutic properties, and have also been found to possess antifungal activity (Bhasker et. al., 1992; Abdou et. al., 2007; Verma et. al., 2008; Birdar et al., 2004 and Dandia et. al., 2006). Due to potential bioactivity of such nitrogen containing heterocyclic spiro compounds, research in this field (Levina et. al. 1960, Bojarski et. al. 1985) has been become more promising and attractive till todate.
Based on these facts, we decided to evaluate the conversion of ketones of nitrogen containing heterocyclic spiro compounds having barbituric acid and thiobarbituric acid moieties into oxime derivatives in the presence of $\mathrm{NH}_{2} \mathrm{OH} \cdot \mathrm{HCl}$ and pyridine under refluxing condition. Product formation was followed by TLC and the spectroscopic data of products were compared to those available in the literature.

\section{Materials and methods}

The UV spectra were run in ethanol using SHIMADZU, UV160A ultraviolet spectrophotometer. The IR spectra were recorded as $\mathrm{KBr}$ pellet using SHIMADZU IR-470 infra-red spectrophotometer in the range of $4000-400 \mathrm{~cm}^{-1}$. The ${ }^{1} \mathrm{H}$ NMR spectra were recorded on a Bruker $400 \mathrm{MHz}$ NMR spectrophotometer. The solvent used was deuterated DMSO. The reactions described in the present paper were carried out primarily following a general procedure (Sandier et. al., 1989) and by changing the reaction conditions whenever necessary.

\section{General Procedure}

A mixture of 1g 7,11-diaryl-2, 4-diazaspiro[5,5]undecane-3oxo (or thioxo)-1,5,9-triones, $1 \mathrm{~g}$ of hydroxylaminehydrogenchloride, $10 \mathrm{~mL}$ of pyrimidine and $10 \mathrm{~mL}$ of absolute alcohol was heated under reflux for 8 hours on a oil bath at $110^{\circ}-115^{\circ} \mathrm{C}$. The solvents were removed by evaporation in a

*Corresponding author. e-mail: uromman@yahoo.com 
Table I. Physical constants and analytical data of the compounds 2a-e

\begin{tabular}{|c|c|c|c|c|c|c|c|c|c|}
\hline Compound & m.p. $\left({ }^{\circ} \mathrm{C}\right)$ & $\begin{array}{c}\text { Yield } \\
\%\end{array}$ & $\begin{array}{c}\mathrm{R}_{\mathrm{f}} \\
\text { value } \\
\text { in tlc }\end{array}$ & $\begin{array}{l}\text { Eluting } \\
\text { Solvent }\end{array}$ & $\begin{array}{c}\% \mathrm{C} \\
\text { Found } \\
\text { (Calcd) }\end{array}$ & $\begin{array}{c}\% \mathrm{H} \\
\text { Found } \\
\text { (Calcd) }\end{array}$ & $\begin{array}{c}\% \mathrm{~N} \\
\text { Found } \\
\text { (Calcd) }\end{array}$ & $\begin{array}{l}\text { Mol. } \\
\text { formula }\end{array}$ & $\begin{array}{c}\mathrm{MS} \\
(\mathrm{m} / \mathrm{z})\end{array}$ \\
\hline $2 \mathrm{a}$ & $244-245$ & 86.0 & 0.82 & $\mathrm{CHCl}_{3}:$ EtOAc, $1: 9$ & $53.83(54.55)$ & $3.95(3.71)$ & $9.62(9.09)$ & $\mathrm{C}_{21} \mathrm{H}_{17} \mathrm{Cl}_{2} \mathrm{~N}_{3} \mathrm{O}_{3} \mathrm{~S}$ & 461.04 \\
\hline $2 b$ & $229-230$ & 78.0 & 0.86 & , & $62.76(63.15)$ & $5.32(5.30)$ & $9.47(9.61)$ & $\mathrm{C}_{23} \mathrm{H}_{23} \mathrm{~N}_{3} \mathrm{O}_{6}$ & 437.16 \\
\hline $2 \mathrm{c}$ & $246-247$ & 79.0 & 0.79 & , & $66.57(66.83)$ & $5.17(5.07)$ & $10.87(11.13)$ & $\mathrm{C}_{21} \mathrm{H}_{19} \mathrm{~N}_{3} \mathrm{O}_{4}$ & 377.14 \\
\hline $2 d$ & $275-276$ & 68.0 & 0.64 &, & $60.91(60.91)$ & $5.38(5.11)$ & $9.98(9.27)$ & $\mathrm{C}_{23} \mathrm{H}_{23} \mathrm{~N}_{3} \mathrm{O}_{5} \mathrm{~S}$ & 453.14 \\
\hline $2 \mathrm{e}$ & $274-275$ & 75.0 & 0.78 & $\mathrm{CHCl}_{3}:$ EtOAc, $9: 1$ & $63.38(64.10)$ & $5.13(4.87)$ & $10.69(10.68)$ & $\mathrm{C}_{21} \mathrm{H}_{19} \mathrm{~N}_{3} \mathrm{O}_{3} \mathrm{~S}$ & 393.11 \\
\hline
\end{tabular}

rotatory vacuum evaporator. The mixture was cooled in an ice-bath and $10 \mathrm{~mL}$ of cold water was added to it. The mixture was stirred until the crystals appeared. The oxime was recrystalised by using absolute alcohol.

\section{Results and discussion}

7,11-Diaryl-2, 4-diazaspiro[5,5] undecane-3-oxo (or thioxo)1,5,9-trione-9-oxime $2 \mathrm{a}-\mathrm{e}$, were prepared by carrying out reactions of 7,11-diaryl-2,4-diazaspiro[5,5] undecane-3-oxo (or thioxo)-1,5,9-triones (Otto et. al., 1976; Osman et. al., 1996; Ahmed et. al., 2005 and Ahmed et. al., 2011) 1a-e with hydroxylaminehydrogenchloride in pyridine and absolute alcohol following a general experimental procedure based on a known method (Sandier et. al., 1989 and Furniss et. al. 1980). The time and temperature of reaction were modified as required. The assignment to the structures of the com- pounds $2 \mathrm{a}$-e was made on the basis of their $\mathrm{UV}, \mathrm{IR},{ }^{1} \mathrm{H}$ NMR, ${ }^{13} \mathrm{C}$ NMR and mass spectral data and elemental analyses.

Compounds 2 a-e showed all expected $\lambda_{\max }$ values in their UV spectra (Table II) in the range of 276-279 $\mathrm{nm}$ due to $\pi \rightarrow \pi^{*}$ and $\mathrm{n} \rightarrow \pi^{*}$ transitions as reported (Bojarski et. al., 1985; Osman et. al., 1996 and Ahmed et. al., 2005) previously. The IR data (Table II) of these compounds showed sharp and broad bands in the range $\left(v_{\max }\right) 3250-3500 \mathrm{~cm}^{-1}$ for the $\mathrm{N}-\mathrm{H}$ and $\mathrm{N}-\mathrm{OH}$ groups. All other typical absorptions for $2 \mathrm{a}-$ e correspond well to expected $v_{\max }$ values (Bojarski et. al., 1985; Osman et al., 1996 and Ahmed et. al., 2005)

In their ${ }^{1} \mathrm{H}$ NMR spectra (Table III) the N-H protons of the compound $2 \mathrm{a}-\mathrm{e}$ at position 2 and 4 are strongly deshielded ( $\delta$ 10.47-11.26) since they are flanked by two $\mathrm{C}=\mathrm{O}$ groups. The non-equivalence of these protons are caused by the

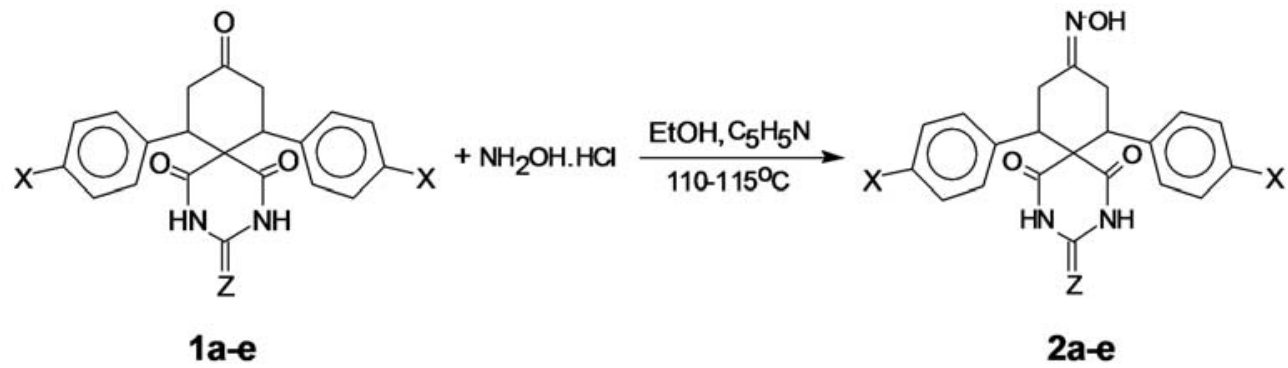

\begin{tabular}{llllll}
\hline Substituents & $\mathbf{2 a}$ & $\mathbf{2 b}$ & $\mathbf{2 c}$ & $\mathbf{2 d}$ & $\mathbf{2 e}$ \\
\hline $\mathrm{X}$ & $4-\mathrm{Cl}$ & $4-\mathrm{OCH}_{3}$ & $\mathrm{H}$ & $4-\mathrm{OCH}_{3}$ & $\mathrm{H}$ \\
\hline $\mathrm{Z}$ & $\mathrm{S}$ & $\mathrm{O}$ & $\mathrm{O}$ & $\mathrm{S}$ & $\mathrm{S}$ \\
\hline
\end{tabular}


Table II. IR and UV spectral data of compounds $2 a-e$

\begin{tabular}{|c|c|c|c|c|c|c|}
\hline \multirow{2}{*}{ Compound } & \multicolumn{5}{|c|}{ IR $v_{\max }$ in $\mathrm{cm}^{-1}$} & \multirow{2}{*}{$\begin{array}{c}\mathrm{UV}, \lambda_{\max }(\mathrm{nm})(\varepsilon) \\
\pi \rightarrow \pi^{*} \& \mathrm{n} \rightarrow \pi^{*} \\
\text { of } \mathrm{C}=\mathrm{C}-\mathrm{C}=\mathrm{O}\end{array}$} \\
\hline & $\mathrm{N}-\mathrm{OH}, \mathrm{N}-\mathrm{H}$ & $\mathrm{C}=\mathrm{O}, \mathrm{C}=\mathrm{N}$ & $\begin{array}{c}\mathrm{C}=\mathrm{C} \text { in conj. } \\
\text { with } \mathrm{C}=\mathrm{O}\end{array}$ & $\begin{array}{c}\mathrm{C}=\mathrm{C} \\
\text { aromatic }\end{array}$ & $\mathrm{N}-\mathrm{O}$ & \\
\hline $2 \mathrm{a}$ & 3300 & 1695,1660 & 1590,1530 & $\begin{array}{l}1485,1380, \\
1180,1085, \\
1440,1360,\end{array}$ & 965 & $279(19792)$ \\
\hline $2 b$ & 3500,3250 & 1690,1640 & 1600,1500 & $\begin{array}{l}1180,1115, \\
1075,1485, \\
1440, \\
1250,1150,\end{array}$ & 940 & $276(1668)$ \\
\hline $2 \mathrm{c}$ & 3450,3250 & 1680,1620 & 1575,1520 & $\begin{array}{l}1065,1440, \\
1250, \\
1180,1115,\end{array}$ & 945 & 279 (9328) \\
\hline $2 d$ & 3400 & 1640,1600 & 1500 & $\begin{array}{l}1075, \\
1025, \\
1425,1380\end{array}$ & 965 & 278 (2308) \\
\hline $2 \mathrm{e}$ & 3250 & 1700,1660 & 1510 & $\begin{array}{l}1330,1150 \\
1070 ; 1030\end{array}$ & 960 & $279(1607)$ \\
\hline
\end{tabular}

anisotropy of the $\mathrm{C}-1$ and $\mathrm{C}-5$ carbonyl groups owing to the geometry of spiro structures as reported (Bojarski et. al., 1985 and Ahmed et. al., 2005) earlier.

Although axial protons are shielded than equatorial protons the axial protons at positions 7, 8, 10 and 11 are considerably

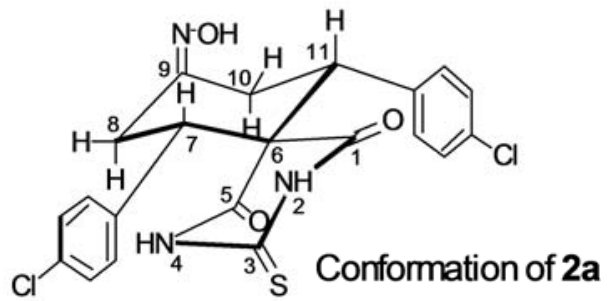

Table III. ${ }^{1} \mathrm{H}$ NMR spectral data of the compounds $2 \mathrm{a}-\mathrm{e} .[(\delta)$ in ppm and $(J)$ in $\mathrm{Hz}]$

\begin{tabular}{llllll}
\hline \multicolumn{1}{c}{ Protons } & $2 \mathrm{a}$ & $2 \mathrm{~b}$ & $2 \mathrm{c}$ & $2 \mathrm{~d}$ & $2 \mathrm{e}$ \\
\hline $2-\mathrm{H}^{*}$ & 10.48 & 11.23 & 11.26 & 10.65 & 10.86 \\
$4-\mathrm{H}^{*}$ & 10.47 & 11.11 & 11.10 & 10.59 & 10.67 \\
$\mathrm{~N}-\mathrm{OH}$ & 10.33 & 10.55 & 10.59 & 10.36 & 10.60 \\
Aromatic & $7.27-7.03$ & $7.00-6.82$ & $7.27-7.08$ & $6.95-6.69$ & $7.35-7.17$ \\
$7-\mathrm{H}_{\mathrm{ax}}, 11-\mathrm{H}_{\mathrm{ax}}$ & 3.95 & 3.88 & 3.89 & 3.88 & 4.01 \\
$J \mathrm{aa}$ & 17.60 & 14.65 & 14.46 & 14.31 & 13.73 \\
$J \mathrm{ae}$ & 4.75 & 4.88 & 4.70 & 4.45 & 4.41 \\
$8-\mathrm{H}_{\mathrm{ax}}, 10-\mathrm{H}_{\mathrm{ax}}$ & 3.57 & 3.48 & 3.52 & 3.40 & 3.51 \\
$J \mathrm{aa}$ & 14.85 & 14.65 & 14.48 & 14.45 & 14.50 \\
Jgem & 15.05 & 15.14 & 15.14 & 15.22 & 2.90 \\
$8-\mathrm{H}_{\text {eq }}, 10-\mathrm{H}_{\text {eq }}$ & 2.51 & 2.40 & 2.45 & 2.40 & 4.74 \\
$J \mathrm{ae}$ & 4.89 & 4.88 & 4.78 & 4.40 & 14.91 \\
$J$ gem & 13.45 & 15.44 & 15.13 & 15.40 & -- \\
$\mathrm{X}$ & -- & 3.68 & --- & 3.70 & $(\mathrm{H})$ \\
& $\left(4^{-}-\mathrm{C} 1\right)$ & $\left(4^{\prime}-\mathrm{OCH}_{3}\right)$ & $(\mathrm{H})$ & $\left(4-\mathrm{OCH}_{3}\right)$ & \\
\hline
\end{tabular}

$* \delta$ values of $2-\mathrm{H}$ and $4-\mathrm{H}$ are interchangeable. 
deshielded and appeared at $\delta 3.40-4.01$. The equatorial protons at positions 8 and 10 resonated at higher field $(\delta 2.40$ 2.51) than the axial protons of these positions. This may be explained by the proximity of the axial protons at $7,8,10$ and 11 positions to the aromatic rings present at positions 7 and 11. The anisotropic effect of $\mathrm{C}=\mathrm{O}$ on $\mathrm{H}_{\mathrm{eq}}$ at $\mathrm{C}-8$ and $\mathrm{C}$ 10 is also responsible for diamagnetic shift of these protons.

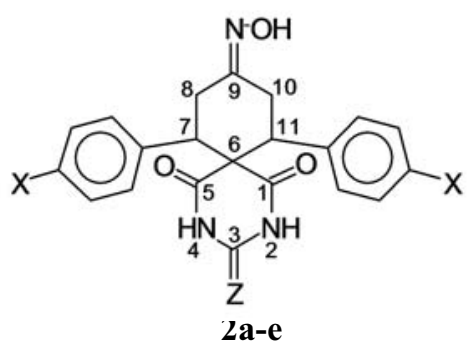

group by a thiocarbonyl group results in a downfield shift (Otto et. al., 1976 and Ahmed et. al., 2005).

For the compounds $2 \mathrm{a}$-e, the chemical shift values of the carbonyl carbon at position C-9 were found at $\delta$ 154.57.79158.85. This value is in good agreement with the literature values (Levy et. al., 1972). The chemical shift values for carbonyl carbon at positions C-1 and C-5 were $\delta 167.20$ 172.53. The non-equivalences of these carbons are caused by the anisotropy of the $\mathrm{C}-1$ and $\mathrm{C}-5$ carbonyl groups owing to the geometry of spiro structures (Bojarski et. al., 1985).

In the compounds $2 \mathrm{a}-\mathrm{e}$, the $\delta$ values (interchangeable) of $\mathrm{C}$ 7 and C-11 were observed at 48.06-50.33. The chemical shift values (interchangeable) of $\mathrm{C}-8$ and $\mathrm{C}-10$ of these compounds were found at $\delta 32.97-33.67$ and $25.86-26.53$ respec-

Table IV. ${ }^{13} \mathrm{C}$ NMR spectral data of the compounds 2a-e. [( $\left.\delta\right)$ in ppm]

\begin{tabular}{|c|c|c|c|c|c|c|c|c|c|c|c|}
\hline Compound & $9-\mathrm{C}$ & $1-C^{*}$ & $5-\mathrm{C}$ & $3-\mathrm{C}$ & Aromatic & $6-\mathrm{C}$ & 7-C* & $11-\mathrm{C}$ & $8-C^{*}$ & $10-\mathrm{C}$ & $\mathrm{X}$ \\
\hline $2 a$ & 156.21 & 168.24 & 168.31 & 170.12 & $\begin{array}{l}138.15,138.10 \\
133.18, \\
133.20, \\
127.15,126.90\end{array}$ & 60.18 & 50.09 & 48.37 & 33.17 & 26.45 & --- \\
\hline $2 b$ & 158.85 & 172.53 & 171.05 & 149.21 & $\begin{array}{l}154.80,130.40 \\
129.09,129.04 \\
114.16\end{array}$ & 60.29 & 49.53 & 48.25 & 33.24 & 26.10 & 55.19 \\
\hline $2 c$ & 154.57 & 172.24 & 170.87 & 149.04 & $\begin{array}{l}138.46,138.40 \\
128.91,128.17\end{array}$ & 59.85 & 50.33 & 49.05 & 32.97 & 25.86 & --- \\
\hline $2 d$ & 158.66 & 167.20 & 167.81 & 169.24 & $\begin{array}{l}128.02,127.98 \\
155.44,131.11 \\
129.21,113.99\end{array}$ & 60.15 & 49.50 & 48.06 & 33.20 & 26.50 & 55.14 \\
\hline $2 \mathrm{e}$ & 155.21 & 167.64 & 167.41 & 168.93 & $\begin{array}{l}139.15,139.10 \\
128.71,128.15 \\
127.90\end{array}$ & 59.78 & 50.19 & 48.87 & 33.67 & 26.53 & --- \\
\hline
\end{tabular}

$* \delta$ values of 1-C, 7-C and 8-C are interchangeable with 5-C, 11-C and 10-C respectively.

The structures of the compounds $2 \mathrm{a}$-e were further confirmed by their ${ }^{13} \mathrm{C}$ NMR spectra (Table III). The chemical shift values are in good agreement with those of reported earlier (Ahmed et. al., 2005) for similar compounds. In the compounds $2 \mathrm{a}-\mathrm{e}$, chemical shifts of carbonyl carbons at C-3 were found to be at $\delta$ 149.04-170.12 and are deshielded due to the resonance of amide functional group. In the compounds $2 \mathrm{a}, 2 \mathrm{~d}$ and $2 \mathrm{e}$, the chemical shifts of thioxo carbon at C-3 were found to be at $\delta 168.93-170.12$. From the above values it is clear that the replacement of a carbonyl tively, slightly lower than those of C-7 and C-11. This is due to the effect of $=\mathrm{N}-\mathrm{OH}$ group which is present next to them.

The ${ }^{13} \mathrm{C}$ shifts of carbons of aromatic rings are assigned on the basis of the correlation chart of ${ }^{13} \mathrm{C}$ NMR spectral data available in the literature (Ahmed et. al., 1998). The spiro carbon C-6 of the compounds $2 \mathrm{a}$-e showed chemical shift values at $\delta$ 59.78-60.29 which are similar to the literature values (Levy et. al., 1972). The value for chloro-carbon in the aromatic ring for the compound $2 \mathrm{a}$ was observed at $\delta 133.18$. 
The high resolution mass spectra of the compounds $2 \mathrm{a}-\mathrm{e}$ showed peaks for their respective molecular ions $\left(\mathrm{M}^{+}\right)$at $\mathrm{m} / \mathrm{z}$ $461.04,437.16,377.14,453.14$ and 393.11 respectively. The isotopic pattern for dichloro compound $2 \mathrm{a}$ was observed in the ratio of 9:6:1. In $2 \mathrm{a}$ the peak for $\mathrm{M}^{+}$was $461.04(27 \%)$, for $\mathrm{M}^{+}+2$ was $463.02(17 \%)$ and that for $\mathrm{M}^{+}+4$ was 465.01 $(3 \%)$. From the fragmentation pattern in these spectra it is observed that most of the prominent peaks were formed due to loss of $\mathrm{CO}, \mathrm{CONH} / \mathrm{CSNH}$, substituted phenyl, tropylium, styryl, methyl, and keten fragments. This is in conformity with the mass spectral fragmentation pattern of those as reported before for 7,11-diphenyl-2, 4-diazaspiro[5, 5] undecane-1,3,5,9-tetraones (Otto et. al., 1976; Osman et. al., 1996 and Ahmed et. al., 2005).

\section{Acknowledgement}

We gratefully acknowledge the help of Prof. Teruo Shinmyozu, Department of Molecular Chemistry, Kyushu University, Fukuoka, Japan for recording mass spectra and determining elemental analyses of our compounds. Our special thanks goes to Prof. Takashi Sugimura, Graduate School of Material Science, University of Hyogo, Japan for recording NMR spectra of the compounds.

\section{References}

Abdou WM, Salem MAI and Barghash RF (2007), A facile access to condensed and spirosubstituted pyrimidine phosphor esters, Arkivoc, XV: 45-60.

Ahmed MG, Ahmed SA, Romman UKR, Mohsin T, Kiuchi F (1998), Synthesis and characterization of some diarylideneacetones (1,5-diaryl-1,4-pentadien-3-ones), Dhaka Univ. J. Sci. 46(2): 253 and references therein.

Ahmed MG, Ahmed SA, Ahmed SM, Hussam A, Hossain MM (2005), Synthesis of 7,11-diaryl-2,4-diazaspiro[5,5] undecane-3-oxo(or thioxo)-1,5,9-trines, Part$1 \mathrm{~J}$. Chem. Res. 10: 622 and references therein.

Ahmed MG, Ahmed SA, Romman UKR, Akhter K, Halim ME, Naher S, Aslam M and Ahmed SM (2011), A one-pot synthesis of 7,11-diaryl-2,4-diazaspiro[5,5] undecane-3-oxo (or thioxo)-1,5,9-triones $J$. Bangladesh Chem. Soc. 24(2): 135-142.

Bhasker Reddy D, Padmavathi V and Ramana Reddy PV (1992), Ind. J. Chem. 31B: 774-778.
Birdar JS and Manjunath SY (2004), Synthesis and biological acticvities of novel 2-(5'-substituted-3'phenylindole-2'-yl)-1,3,4-oxadiazino [5,6-b]indole and 3-(5'substituted-3'-phenylindole-2'-amido) Spiro (indol3",2,thiazolodine)-2",4-diones Indian J. Chem. 43B: 389.

Bojarski JT, Mokrosz JL, Barton HJ. and Paluchowaka M H (1985), Advances in Heterocyclic Chemistry (Review Article), 38: 229-297 and references therein.

Dandia A, Singh R, Khaturia S, Merienne C, Morgant and G. Loupy A (2006), Efficient microwave enhanced regioselective synthesis of a series of benzimidazolyl/ triazolyl spiro[indole-thiazolidinones] as potent antifungal agents and crystal structure of spiro[3H-indole3,2 -thiazolidine]-3 (1,2,4-triazol-3-yl) 2,4 (1H)-dione, Bioorg. Med. Chem. 14: 2409.

Furniss BS, Hannaford AJ, Rogers V, Smith PWG and Tatchell AR (1980), Vogel's Text Book of Practical Organic Chemistry, 4th ed. (Longman Group Ltd. London) 1980, pp 1113.

Furuya Y, Ishihara K and Yamamoto H (2005), Cyanuric chloride as a mild andactive Beckmann rearrangement catalyst. J. Am. Chem. Soc. 127: 11240-11241.

Greene TW and Wuts PGM (1999), Protective Groups in Organic Synthesis, 3rd ed. (Wiley: Toronto), 1999, pp 355-358.

Levina RY and Velichko F K (1960), Advances in the chemistry of barbituric acids, Russ. Chem. Rev. (Review Article) 29: 437.

LevyGC and Nelson GL (1972), Carbon-13 Nuclear Magnetic Resonance for Organic Chemists (John Wiley \& Sons, New York) 1972, pp 133.

Osman AN, Kandeel MM, Said MM and Ahmed EM (1996), Synthesis and anticonvulsant activity of some spiro compounds derived from barbituric acid and thiobarbituric acids. Part-I. Indian J. Chem., 35B(10): 1073.

Otto HH and Triepel J (1976), Synthesis and structure of 7,11-diphenyl-2,4-diazaspiro[5.5] undecan-1,3,5,9tetraones, I. Liebigs Ann. Chem. 1982. 
Ramalingan C and Park YT (2007), Mercury-catalyzed rearrangement of ketoximes into amides and lactams in acetonitrile. J. Org. Chem. 72: 4536-4538.

Sandier SR and Karo W (1989), Organic Functional Group Preparations, 2nd ed. (Academic Press: San Diego), 1989, pp 431-476.

Song BA, Liu XH, Yang S, Hu DY, Jin LH and Zhang YT (2005), Recent advance in synthesis and biological activity of oxime derivatives. Chin. J. Org. Chem. 25(5): 507-525.
Verma A and Saraf SK (2008), 4-thiazolidinone--a biologically active scaffold, Eur. J. Med. Chem. 43: 897.

Whitesell JK and Whitesell MA (1983), Alkylation of Ketones and Aldehydes via their Nitrogen Derivatives. Synthesis 7: 517-536.

Received: 19 March 2012; Revised: 11 October 2012; Accepted: 14 October 2012. 